\title{
Relationship between executive functions and impulsive behavior in adolescents: Comparative study
}

\author{
Lizbeth Quintero Reynaga, ${ }^{1}$ Gilberto Galindo Aldana, ${ }^{2}$ Julieta Bonilla ${ }^{3}$ Brenda Viridiana Rabago Barajas ${ }^{4}$
}

1 Facultad de Psicología, Centro de Enseñanza Técnica y Superior, Ciudad de México, México.

2 Laboratorio de Neurociencias y Cognición, Facultad de Ingeniería y Negocios, Salud Mental, Grupo de Investigación de Profesiones y Sociedad, Universidad Autónoma de Baja California, México.

3 Departamento de Psicología, Universidad Xochicalco, Ciudad de México, México.

${ }_{4}^{4}$ Departamento de Psicología, Universidad Autónoma de Guadalajara, México

\section{Correspondence:}

Lizbeth Quintero Reynaga

Dirección de maestría en

Neuropsicología, Cetys Universidad.

Calz. Cerys S/N, Rivera, 21259

Ciudad de Mexicali, México.

Phone: $686123-7513$

Email: lizquinteror@gmail.com

Received: 14 October 2019

Accepted: 21 April 2020

Citation:

Quintero Reynaga, L., Galindo Aldana, G., Bonilla, J., \& Rabago Barajas, B. V. (2020). Relationship between executive functions and impulsive behavior in adolescents: Comparative study. Salud Mental, 43(4), 175-180

DOI: $10.17711 /$ SM.0185-3325.2020.024

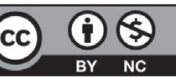

\begin{abstract}
Introduction: Impulsivity can be directly related to maladaptive and disruptive behaviors; specifically, during adolescence, impulsivity is associated with behavioral and social problems, and it has been found that some behavioral difficulties are related to neuropsychological dysfunction of the prefrontal cortex, which is responsible for regulating impulse control and executive functions. Objective. To compare the relationships among executive functions, particularly inhibitory control, behavioral planning and behavioral flexibility, in adolescents between 13 and 15 years old with and without impulsivity. Method. This study was developed using an analytical, comparative design. The sample consisted of 62 participants whose impulsivity was measured using the BIS-11-A Impulsiveness Scale and whose data were compared with normative data from the same sample size. Executive functions were evaluated using the Tower of London test, Modified Wisconsin Card Sorting Test (M-WCST), Trail Making Test (TMT) and Stroop test. Results. Young people between 13 and 15 years old who exhibited impulsive behavior showed impairment in the executive functions studied, such as inhibitory control, cognitive flexibility, and behavioral planning. Discussion and conclusion. There is a direct correlation between impulsive behaviors and executive functions during adolescence. The results found here support the development of potential intervention protocols based on executive functioning.
\end{abstract}

Keywords: Executive function, impulsive behavior, cognition, adolescent.

\section{RESUMEN}

Introducción. La impulsividad puede relacionarse directamente con conductas desadaptativas y disruptivas; en el caso concreto del periodo adolescente, la impulsividad se asocia con problemas conductuales y sociales agregados, se ha encontrado que algunas dificultades en la conducta se relacionan con una disfunción neuropsicológica de la corteza prefrontal, la cual se encarga de regular el control de impulsos y de las funciones ejecutivas. Objetivo. Describir la relación entre el funcionamiento ejecutivo, particularmente control inhibitorio, la planeación conductual y la flexibilidad conductual en adolescentes de edades entre 13 y 15 años que presentan un índice de impulsividad contra datos de adolescentes que no presentan impulsividad. Método. El estudio se desarrolló mediante un diseño analítico, tipo comparativo. La muestra se compuso de 62 participantes con índice de impulsividad medida a través de la BIS-11-A, muestra que después se comparó con una muestra de igual tamaño procedente de los datos normativos. Se realizó la evaluación de las funciones ejecutivas con prueba Torre de Londres, M-Wisconsin, Trail Making Test y Test Stroop. Resultados. Se identificó que los jóvenes de entre 13 y 15 años que muestran conducta impulsiva presentaron también una alteración en las funciones ejecutivas estudiadas, tales como control inhibitorio, flexibilidad cognitiva y planeación conductual. Discusión y conclusión. Se identificó que existe una correlación directa entre las conductas impulsivas y las funciones ejecutivas evaluadas en la etapa de la adolescencia. Los resultados encontrados aquí pueden apoyar la construcción de potenciales protocolos de intervención basados en el funcionamiento ejecutivo.

Palabras clave: Control inhibitorio, flexibilidad conductual, planeación conductual, desarrollo. 


\section{INTRODUCTION}

Adolescence is a critical developmental age characterized by particular mental health issues. Executive function impairments may lead to several problems with social interactions and risky behaviors (Papazian, Alfonso, \& Luzondo, 2006; Rojas Pérez, Szymanski Peters, Romero José, \& Sánchez Muñoz, 2015; Broche-Pérez \& Cortés-González, 2015). Currently, the World Health Organization estimates that $17 \%$ of the Mexican population have at least one mental disorder such as impulse control disorders, depression, borderline personality disorders, antisocial disorders, and other psychopathological conditions are present in this population (Mas Colombo, Risueño, \& Motta, 2003); one in four individuals suffers from at least one of these conditions once in his/her lifetime, only one in five receives treatment (Oficina de Información Científica y Tecnológica para el Congreso de la Unión [INCyTU], 2018). However, only a few programs present high clinical neuropsychological sensitivity for detecting risk behavior and its association with neuropsychological processing (Galindo-Aldana et al., 2020).

Impulsive behaviors acquire relevance in the scientific realm as a way to explain the differences between normal and pathological behaviors, as well as in their relationship with various mental disorders. These findings are related to the genetic and neurobiological fields (Salvo \& Castro, 2013). Advances in research on the human brain are increasing and have reached a point where neuroscience can be justifiably considered the biomedical foundation of psychiatry. This has allowed neuroscience to offer important contributions to psychiatry for understanding and caring for patients with neuropsychiatric conditions (Hales, Yudofsky, \& Talbott, 1996).

Impulsivity, as an objective expression of mental health, can be analyzed as one of the most evident factors in infant development; however, it can also be considered the origin of disruptive behaviors in childhood and adolescence without losing sight of its two-dimensional nature: on the one hand, it serves as a behavioral factor related to disinhibition and motor restlessness, and on the other, it serves as a cognitive factor that involves a lack of foresight and behavior planning (Corbí \& Pérez-Nieto, 2011).

In recent decades, neuropsychological research has suggested that altered executive functions are directly correlated with certain impulsive behaviors (Broche-Pérez \& Cortés-González, 2015; Papazian et al., 2006; Rojas Pérez et al., 2015; Solis \& Quijano, 2014). The neuropsychology of development refers to the fact that these executive functions are constituted not in a gradual and consistent manner but with varied plateaus and abrupt changes. Therefore, when analyzing these functions during adolescence (the period of the greatest biological and functional transition in human beings), they can be of particular interest and contribute to the field of neuropsychology for evaluative and interventional purposes (Flores-Lázaro, Castillo-Preciado, \& Jiménez-Miramonte, 2014).

According to a study based on the analysis of 50 yearfollow-up for an adolescent intervention program in Mexico, it was found out that impulsive behavior represent a significant health challenge in the youth (Fernández-Cáceres, 2019). Preventive programs have been implemented at strategic locations in Mexico, but their scope still needs to be improved to include neuropsychological diagnosis and intervention procedures that may contribute to risk behavior reduction in adolescence. Therefore, the present study aimed to compare executive functions in adolescents who exhibit impulsive behaviors with those who do not exhibit them in order to contribute to the description of this cognitive process in the Mexican population. This study also aimed to contribute empirical evidence and thus, in the future, to provide additional support to the development of an intervention plan for executive functioning within mental health institutions in Mexico and decrease the impulsivity index during adolescence.

\section{METHOD}

\section{Study design}

This study was developed with an analytical, comparative design via a quantitative approach because it contrasts the results of the executive functions of adolescents who exhibit impulsive behaviors with those of adolescents who do not exhibit these behaviors.

\section{Participants}

Sample selection was performed using the probability sampling method; systematic random sampling was carried out using a population of 211 Mexican males and females aged 13 to 15 years attending the Institute of Psychiatry of the State of Baja California (IPEBC Spanish abbreviation) in Mexicali city. A confidence level of $95 \%$, a sample size of 102 , and a $15 \%$ adjustment for sample loss were established, yielding a total of 124 individuals. Participants were classified in two groups according to the score from the Barrat Impulsivity Scale (BIS-11-A). An impulsive group of 62 participants and a non-impulsive group, made up by the remaining participants were examined for executive planning (Artiola Fortuny, Hermosillo Romo, Heaton, \& Pardee, 2000), flexibility, and inhibitory control (Arango-Lasprilla et al., 2017b). The inclusion criteria were as follows: voluntary participation in the study, 13 to 15 years old at the time of the study, exhibiting risk behaviors according to the BIS-11-A questionnaire, and assessed at the IPEBC Children's Clinic. Participants who were previously diagnosed with any of the following by a psychiatrist were excluded: intellectual development disor- 
der, autism spectrum disorder, disease of the nervous system, and drug use (marijuana, cocaine, and methamphetamines).

\section{Measurements}

For impulsivity measurements, the BIS-11-A was used, which consists of 30 Likert-type items for which participants report on the frequency of different behaviors; the cut-off point was 32. This tool has shown validity and reliability with a Cronbach's alpha of .87 for internal consistency of ordinal data in the BIS-11-A (Martínez-Loredo, Fernández-Hermida, Fernández-Artamendi, Carballo, \& García-Rodríguez, 2015).

For executive function measurements, the Tower of London Test was used. This test is a self-administered neuropsychological test designed to assess the resolution of higher-order problems, specifically the ability for executive planning, in children and adults (Culbertson \& Zillmer, 2001). Additionally, Stroop's Test was applied (with the word condition and color condition), with the main objective of measuring the ability of an individual to control the interference produced by previously automated and unintentional responses in relation to other controlled and voluntary responses demanded by the situation (Arango-Lasprilla et al., 2017b). The Modified Wisconsin Card Sorting Test (M-WCST) was also used, which consists of discovering an underlying rule or sorting criterion by pairing a series of cards that varies according to three basic categories (shape, color, and number). The M-WCST can be considered a measure of executive function because it requires the ability to develop and maintain problem-solving strategies that are appropriate for achieving an objective through conditions involving stimulus changes (Arango-Lasprilla et al., 2017a).

The Trail Making Test (TMT) provides information on visual attention, speed, motor inhibition, flexibility, and task switching. The test consists of two parts in which the task is to connect points distributed at random.

\section{Procedures}

The study population was integrated with adolescents between the ages of 13 and 15 years who attended to the Child Psychology and Psychiatry Department of IPEBC from August to October 2018. All the adolescents and their parents were invited to participate voluntarily and gave their informed assent and consent, respectively. Participants who agreed were administered the BIS-11-A to determine whether they exhibited impulsive behaviors.

Subsequently, standard neuropsychological tests were applied during a 1-hour and 30-minute session with environmental control conditions. A professional psychologist with five years' expertise in neuropsychological assessment and enough knowledge about the procedures carried out the tests.

\section{Statistical analysis}

For the statistical analysis, a comparison of each variable between groups was performed; Levene's Test was used to determine the homogeneity of the variance.

The qualitative variables are described using frequencies (percentages) with 95\% confidence intervals were calculated for the studied parameters. To study the differences between means, Student's t-test was used to compare two independent groups. The level of significance was set at $p<.05$.

\section{Ethical considerations}

Informed assent and consent were obtained from all participants and their parents after the principal investigator provided a broad description of the study, explaining that the research will be anonymous and confidential. This study was approved by the Ethics Committee of the IPEBC (ID CONBIOETICA02CEI1020150416). This study followed the guidelines of the Helsinki Declaration to carry out research with human participants. The researchers declare no conflicts of interest or economic motives related to this study.

\section{RESULTS}

Impulsive and non-impulsive groups were proportionally equal in terms of age (mean $=13.76$ years old; standard deviation $[S D]=.703$ ) and education level, details are shown in Table 1. The adolescents who showed impulsive behavior were processed according to criteria for each neuropsychological task and compared to non-impulsive adolescents and their corresponding Mexican norms (Table 2). Comparisons of the different functions evaluated showed, in several areas, statistically significant differences between the impulsive and non-impulsive group, though both groups were within percentiles for their age.

Table 1

Educational attainment, sex, and impulsiveness measures in impulsive and non impulsive groups

\begin{tabular}{llcc}
\hline & & \multicolumn{2}{c}{ Group } \\
\cline { 3 - 4 } & & $\begin{array}{c}\text { Impulsive } \\
\text { behavior }\end{array}$ & $\begin{array}{c}\text { Non impulsive } \\
\text { Behavior }\end{array}$ \\
\hline Education level & 1st year & 24 & 24 \\
Junior high school & 2nd year & 27 & 28 \\
& 3rd year & 11 & 10 \\
Sex & Male & 44 & 43 \\
& Female & 18 & 19 \\
\multirow{3}{*}{ Barratt } & Mean (SD) & $57.21(15.15)$ & $49.3(14.9)$ \\
\hline
\end{tabular}

Note: $S D$, standard deviation 
Table 2

Comparisons scores between the group of adolescents with and without impulsive behavior and percentile values according to Mexican norms for each neuropsychological task

\begin{tabular}{|c|c|c|c|c|c|}
\hline & \multicolumn{2}{|c|}{ Mean (SD) } & \multirow[b]{2}{*}{$t$} & \multirow[b]{2}{*}{$F$} & \multirow[b]{2}{*}{$p$} \\
\hline & Impulsive group & Non impulsive group & & & \\
\hline Stroop word (DS) & $80.45(15.6)$ & $90.02(2.1)$ & -4.767 & 48.315 & $<.001$ \\
\hline Stroop word $(P)$ & $41.88(25.2)$ & $50.48(6.1)$ & -2.607 & 90.378 & .01 \\
\hline Stroop color (DS) & $52.56(12.8)$ & $66.27(2.2)$ & -8.301 & 49.313 & .011 \\
\hline Stroop color $(\mathrm{P})$ & $33.12(26.2)$ & $55.32(6.9)$ & -6.125 & 118.616 & $<.001$ \\
\hline Stroop color-word (DS) & $30.91(10)$ & $41.44(1.3)$ & -8.163 & 56.177 & $<.001$ \\
\hline Stroop color-word $(\mathrm{P})$ & $30.33(13.7)$ & $51.12(3.1)$ & -6.335 & 96.356 & $<.001$ \\
\hline TMT A (DS) & $54.37(18.4)$ & $21.28(.6)$ & 10.410 & 83.162 & $<.001$ \\
\hline TMT A (P) & $16.41(10.6)$ & $47.34(8.6)$ & -14.420 & 115.372 & $<.001$ \\
\hline TMT B (DS) & 125.2 & $40.37(26)$ & 9.629 & 58.504 & $<.001$ \\
\hline TMT B (P) & $10.80(10.13)$ & $48.67(2.98)$ & -30.465 & 93.071 & $<.001$ \\
\hline Wisconsin error (DS) & $16.46(10.2)$ & $9.80(.6)$ & 5.133 & 156.498 & $<.001$ \\
\hline Wisconsin error $(\mathrm{P})$ & $41.22(28.9)$ & $58.487(7.1)$ & -2.390 & 253.434 & .018 \\
\hline Wisconsin perseverative error (DS) & $5.67(7.4)$ & $2.68(.18)$ & 3.147 & 26.416 & .002 \\
\hline Wisconsin perseverative error $(\mathrm{P})$ & $45.95(24.6)$ & $56.29(3.9)$ & -1.292 & 146.656 & .199 \\
\hline Wisconsin categories (DS) & $3.8(1.8)$ & $5.03(.11)$ & -5.127 & 205.939 & $<.001$ \\
\hline Wisconsin categories $(\mathrm{P})$ & $40.88(31)$ & $49.16(3.75)$ & -2.285 & 366.778 & .024 \\
\hline Tower of London correct designs (DS) & $3.2(1.6)$ & 5 & -8.586 & 63.628 & $<.001$ \\
\hline Tower of London correct designs $(\mathrm{P})$ & $88.56(15.3)$ & $103(.19)$ & -5.782 & 68.610 & $<.001$ \\
\hline Tower of London total movement (DS) & $35.53(29.32)$ & $24(1.6)$ & 3.046 & 23.105 & .003 \\
\hline Tower of London total movement $(\mathrm{P})$ & $87.38(16.9)$ & $98(3)$ & -5.772 & 150.615 & $<.001$ \\
\hline \multicolumn{6}{|l|}{ Tower of London } \\
\hline Start time (DS) & $31.61(11.3)$ & $42(7.1)$ & -7.117 & 107.337 & $<.001$ \\
\hline \multicolumn{6}{|l|}{ Tower of London } \\
\hline Start time $(P)$ & $98.86(9.5)$ & 97 (4) & -0.959 & 30.488 & .340 \\
\hline Tower of London, Execution time (DS) & $270.61(107)$ & $209(10)$ & 4.442 & 102.934 & $<.001$ \\
\hline Tower of London, Execution time (P) & $88.86(17.6)$ & $105(4)$ & -4.872 & 155.380 & $<.001$ \\
\hline Tower of London violation of the rules (DS) & $1.35(3.1)$ & 0 & 3.359 & 32.340 & .001 \\
\hline Tower of London violation of the rules $(\mathrm{P})$ & $87.73(23.8)$ & $95.41(11)$ & -3.980 & 255.767 & $<.001$ \\
\hline
\end{tabular}

Notes: DS, direct score; P, percentile value according to Mexican norms; SD, standard deviation.

\section{DISCUSSION AND CONCLUSIONS}

The present study aimed to compare the executive functioning of adolescents who showed impulsive behaviors with that of peers of the same age without impulsivity behaviors. The results obtained showed significant differences between adolescents who exhibited impulsive behavior measured through the impulsivity index scale and adolescents who did not exhibit impulsive behavior. Adolescents with impulsivity scores exhibited lower scores in the executive functions studied, such as inhibitory control, cognitive flexibility, and behavioral planning, which are consistent with the results reported by Broche-Pérez and Cortés-González (2015), who stated that a deficit in certain executive functions facilitates the appearance of socially inappropriate behaviors, the inability to plan actions and solve problems, and increased aggressiveness and impulsive behaviors. Likewise, Orjales (2000) suggested that a deficit in execu- tive functioning, such as a lack of inhibition, reflects a deficiency in an individual's capacity to self-regulate. In turn, Andreu, Peña, and Abilleira (2012) stated that impulsivity is one of the most important aspects in the adolescence, both as a behavioral factor referred to as disinhibition and motor restlessness and as a cognitive factor, that implies a significant lack of foresight and behavior planning.

Based on the test used, the results revealed significant differences in executive functioning, with the group that showed impulsivity exhibiting lower executive performance scores than the group that did not show impulsivity. Some studies have described the likelihood of a relationship between executive functions and impulsive behaviors, characterized by an inadequate, poorly planned behavior that often puts an individual at risk (Betancourt Ocampo \& García Campos, 2015).

Regarding inhibitory control, there was a difference between the groups of adolescents, both in verbal and executive 
inhibitions, which coincides with results reported previously (Acosta López et al., 2010), which found that failures in cognitive inhibition are linked to the internalization of problems, while failures in behavioral inhibition are linked to the externalization of behaviors and are based on an individual's ability to inhibit their behavioral response to a stimulus.

Regarding cognitive flexibility, the results of this study indicate less efficient performance in adolescents with impulsivity; compared with the control group, the adolescents with impulsivity had difficulty inhibiting response patterns and changing strategies, as also observed by Flores-Lázaro and Ostrosky-Solís (2008). Even though in the variable Wisconsin perseverative errors, these differences were not statistically significant for comparing normative data from both groups.

Last, the results revealed that impulsivity was related to impaired behavioral planning because participants exhibiting impulsive behaviors presented deficits in the processing of sequentially presented information to achieve a particular goal, which is consistent with the results reported by Orozco-Cabal and Herin (2008). Regarding the Tower of London Test, comparisons showed significant differences in total movement, execution time, and violation of the rules between both groups.

The strengths of this study are that it was possible to reach a statistically significant sample size and to measure the intended outcome with properly parameterized instruments for this population. Although, the sample used was obtained from a single environment, the Institute of Psychiatry of the State of Baja California, and several of the participants were referred to this institution for problems caused by such behavior. It will be important to determine whether these results could be generalized to adolescents from other environments.

By addressing the objectives of the study, we can conclude that, as indicated in the hypothesis, there are differences in executive functions (inhibition, cognitive flexibility, and planning) between participants who exhibit impulsive behavior and those who do not exhibit such behavior during the adolescence. It is recommended that a future study analyze impulsive behavior in children and adolescents, with the aim of reviewing whether the link between disinhibition, restlessness, and lack of behavioral planning regarding the executive functions studied are expressed differently at early ages.

It is important to establish the use of neuropsychological tests to support the in-depth clinical analysis of adolescents with impulsive behaviors and to identify neuropsychological tests, such as those used in this study, that are good predictors of neurodevelopment underachievement in the adolescence, which can lead to the establishment of recognition protocols at the level of executive functions and behavioral measurements that could be developed for this type of patients (Romer, 2010).

Finally, it is necessary to build protocols to favor executive functioning in adolescence; it would imply improving the ability to organize the sequences of behavior and orientation towards achieving the desired objectives. It is considered relevant that concerns regarding executive functions are carried out from an early age, before the processes have had their maximum neurobiological installation in the frontal regions, with the intention of favoring the sequence of normal development of these functions (Berthelsen, Hayes, White, \& Williams, 2017).

\section{Funding}

None.

\section{Conflicts of interest}

The authors declare they have no conflicts of interest.

\section{Acknowledgments}

We thank the Institute of Psychiatry of the State of Baja California for allowing this project to be carried out in its facilities.

\section{REFERENCES}

Acosta López, J., Cervantes Henríquez, M., Sánchez Rojas, M., Núñez Barragán, M., Puentes Rozo, P., Aguirre Acevedo, D., \& Pineda Salazar, D. (2010). Alteraciones del control inhibitorio conductual en niños de 6 a 11 años con TDAH familiar de Barranquilla. Psicogente, 13(24), 274-291.

Andreu, J., Peña, M., \& Abilleira, M. P. (2012). Análisis de la impulsividad en diferentes grupos de adolescentes agresivos. International Journal of Psychology and Psychological Therapy, 12(3), 441-452.

Arango-Lasprilla, J. C., Rivera, D., Nicholls, E., Aguayo Arelis, A., García de la Cadena, C., Peñalver Guia, A. I., ... Sánchez-SanSegundo, M. (2017a). Modified Wisconsin Card Sorting Test (M-WCST): Normative data for Spanish-speaking pediatric population. NeuroRehabilitation, 41(3), 617-626. doi: 10.3233/NRE172242

Arango-Lasprilla, J. C., Rivera, D., Ramos-Usuga, D., Vergara-Moragues, E., Montero-Lopez, E., Diaz, L. A., ... Ferrer-Cascales, R. (2017b). Trail making test: Normative data for the Latin American Spanish-speaking pediatric population. NeuroRehabilitation, 41(3), 627-637. doi: 10.3233/NRE-172247

Artiola Fortuny, L., Hermosillo Romo, D., Heaton, R. K., \& Pardee III, R. E. (2000). Manual de normas y procedimientos para la bateria neuropsicológica en espanol. Tucson (AZ): Swets \& Zeitlinger.

Berthelsen, D., Hayes, N., White, S., \& Williams, K. E. (2017). Executive Function in Adolescence: Associations with Child and Family Risk Factors and SelfRegulation in Early Childhood. Frontiers in Psychology, 8, 903. doi: 10.3389/ fpsyg.2017.00903

Betancourt Ocampo, D., \& García Campos, S. R. (2015). La impulsividad y la búsqueda de sensaciones como predictores de la conducta antisocial en adolescentes. Enseñanza e Investigación en Psicología, 20(3), 309-315.

Broche-Pérez, Y., \& Cortés-González, L. (2015). Funciones ejecutivas en adolescentes con conducta antisocial. Archivos de Neurociencias, 20(2), 109-115.

Corbí, B., \& Pérez-Nieto, M. A. (2011). Relación entre impulsividad y ansiedad en los adolescentes. Revista Electrónica de Motivación y Emoción. Revista Electrónica de Motivación y Emoción, 37(14), 109-122.

Culbertson, W. C., \& Zillmer, E. (2001). Tower of London-Drexel University (TOL DX). Manual Técnico. Toronto, Canada: Multi-Health Sistems.

Fernández-Cáceres, C. (2019). Centros de Integración Juvenil 1969-2019: 50 años, historia, retos y perspectivas. Revista Internacional de Investigación en Adicciones, 5(1), 3-5. doi: 10.28931/riiad.2019.1.01

Flores-Lázaro, J. C., \& Ostrosky-Solís, F. (2008). Neuropsicología de lóbulos frontales, funciones ejecutivas y conducta humana. Revista Neuropsicología, Neuropsiquiatría y Neurociencias, 8(1), 47-58. 
Flores-Lázaro, J. C., Castillo-Preciado, R. E., \& Jiménez-Miramonte, N. A. (2014). Desarrollo de funciones ejecutivas, de la niñez a la juventud. Anales de Psicología, 30(2), 463-473. doi: 10.6018/analesps.30.2.155471

Galindo-Aldana, G., Ledesma-Amaya, L., García-Gomar, L., Negrete-Cortes, A., Galarza-Del-Ángel, J., \& Padilla-López, A. (2020). Risk behavior and emotionally interfered working memory in adolescents from rural areas: Normative data and correlations. Psychology \& Neuroscience, 13(1), 61-75. doi: $10.1037 /$ pne0000182

Hales, R. E., Yudofsky, S. C., \& Talbott, J. A. (1996). Tratado de Psiquiatría. American Psychiatric, Inc. Barcelona, España: Ancora, S. A.

Martínez-Loredo, V., Fernández-Hermida, J. R., Fernández-Artamendi, S., Carballo, J. L., \& García-Rodríguez, O. (2015). Adaptación y validación española de la escala de Impulsividad de Barratt en adolescentes tempranos (BIS-11-A). International Journal of Clinical and Health Psychology, 15(3), 274-282. doi: 10.1016/j.ijchp.2015.07.002

Mas Colombo, E., Risueño, A., \& Motta, I. (2003). Función ejecutiva y conductas impulsivas. In: Saiz Ruiz, J. IV Congreso Virtual de Psiquiatría - Interpsiquis. pp. 5-15.

Oficina de Información Científica y Tecnológica para el Congreso de la Unión (INCyTU). (2018). Salud Mental en México, 07. Retrieved from www. foroconsultivo.org.mx

Orjales Villar, I. (2000). Deficit de atención con hiperactividad: El modelo híbrido de las funciones ejecutivas de Barkley. Revista Complutense de Educación, 11(1), $71-84$
Orozco-Cabal, L. F., \& Herin, D. (2008). Neurobiología de la impulsividad y los trastornos de la conducta alimentaria. Revista Colombiana de Psiquiatría, $37(2), 207-219$

Papazian, O., Alfonso, I., \& Luzondo, R. J. (2006). Trastornos de las funciones ejecutivas. Revista de Neurología, 42(Supp3), S45-S50. doi: 10.33588/ rn.42S03.2006016

Rojas Pérez, C., Szymanski Peters, M. G., Romero José, M. F., \& Sánchez Muñoz, T. T. (2015). Relación entre funciones ejecutivas y habilidades sociales en adolescentes: Un estudio piloto. Revista Intercontinental de Psicología y Educación, 17(2), 167-183.

Romer, D. (2010). Adolescent risk taking, impulsivity, and brain development: implications for prevention. Developmental Psychobiology, 52(3), 263-276. doi: $10.1002 /$ dev. 20442

Salvo-G, L., \& Castro-S, A. (2013). Confiabilidad y validez de la escala de impulsividad de Barratt (BIS-11) en adolescentes. Revista Chilena de NeuroPsiquiatría, 51(4), 245-254. doi: 10.4067/S0717-92272013000400003

Solis, V., \& Quijano, M. C. (2014). Rehabilitació neuropsicológica en un caso de TDAH con predominio impulsivo. Revista Chilena de Neuropsicología, 9(2), 67-71. doi: 10.5839/rcnp.2014.0902E.05 